\title{
O Estado e a educação na perspectiva da classe trabalhadora
}

\author{
Fernando Ponte*
}

\section{Resumo}

Neste artigo, destacam-se alguns autores que questionam a categoria trabalho como centralidade e outros que criticam tal posição, nesta direção, procura-se situar outra abrangência para o debate. Trata-se de sugerir que, sem considerar o caráter históricocultural, o trabalho, como princípio positivo, torna-se uma idealização inclusive como princípio educativo reivindica a perspectiva da classe trabalhadora. Ou seja, se não se considera seu conceito como criaçáo de valor, a emancipação formativa reduz-se ao plano da consciência, perde sua ontologia. Nesse âmbito, a centralidade política do capital é a substância do que parece ser a retomada da centralidade do trabalho. O seu real antagonismo é colocar o Estado e a educaçáo sob outra centralidade, a teoria revolucionária como princípio educativo orientador.

Palavras-chave: Trabalho. Educação. Crise.

*Doutor em Psicologia Social pela Pontifícia Universidade Católica de São Paulo (PUC/SP). Professor do Programa de Pós-Graduação em Sociologia Política da Universidade Federal de Santa Catarina (UFSC). 


\section{Introdução}

A abordagem do tema proposto pode estar sujeita a algumas ciladas, o que dificulta uma intervençáo que busca, de forma resumida, não ser uma mera repetição de chavôes ou lugares-comuns. Noutra maneira de dizer, nem sempre, para o pensamento crítico ${ }^{1}$, o mais consequente é formular questóes cujas respostas sejam as mais aceitáveis. Esse tipo de convençáo tornou-se mais usual e predominante nas universidades, como condição para a formação e carreira acadêmica. $\mathrm{O}$ que torna determinados temas indigestos e suas abordagens situadas como fora de lugar.

Nas diferentes perspectivas metateóricas e seus correspondentes ideológicos antirrevolucionários ${ }^{2}$, o conceito de classe social estaria fora de lugar porque as relações sociais identitárias, ou "forma de vida", e não mais as "distributivas" seriam as explicativas dos fenômenos sociais. Larga bibliografia na sociologia e filosofia moral que tem abordado a questáo sob essa perspectiva é divulgada também no Brasil ${ }^{3}$, remetendo o debate à chamada atualização da sociedade pós-industrial, sociedade do não trabalho ou outras denominaçôes próximas.

Quase nessa mesma direção, como sociedade pós-industrial Alain Touraine não advoga exatamente a sociedade sem o trabalho, mas algo como uma sociedade que não se baseia mais no trabalho produtivo, "que se opunha diretamente ao capitalista" (TOURAINE, 1970, p. 15).

$\mathrm{O}$ autor refere-se à denominada sociedade pós-industrial como explicada pela categoria mutação, algo que possibilita compreender como a resistência da vida privada não se define mais no quadro do trabalho perante um poder de integração e de manipulação: "[...] é o conjunto da personalidade que se mobiliza". "Duma sociedade à outra" (TOURAINE, 1970, p. 19), a ruptura com o passado ainda tem movimentos que se apoiam em análises herdadas da situação pretérita, mas tendendo, cada vez mais, a uma fraca institucionalização dos conflitos originados do mundo do trabalho.

Jürgen Habermas (2001), em 1981, com seu livro Teoria da açâo comunicativa, foi um dos autores que mais se notabilizaram ao elaborar uma teoria social alternativa aos clássicos da sociologia do trabalho (Marx, Durkheim e Weber). Sua teoria da ação postula desenvolver um conceito de racionalidade capaz de emancipar-se, integrando os paradigmas de sistema e mundo da vida, reconstruindo o projeto da ilustração onde a subjetividade 
constrói a objetividade: pela linguagem mediadora da intersubjetividade, que requer conceitos comuns.

Nessa formulação, o trabalho perde o alcance como categoria na medida em que sua base, a coisificação ${ }^{4}$ "prejulga as relaçôes com o mundo" (HABERMAS, 2001, p. 453), sem compreender a maneira como os sujeitos dotados de linguagem referem-se ao mundo social e ao mundo subjetivo próprio de cada um. Seria, na referência a Henriche e na crítica a Adorno, uma "autoconsciência enceguecida". Para Habermas (2001), diferentemente da razão instrumental, a razão comunicativa não pode submeter-se sem resistências. A perspectiva utópica, como diz, de reconciliação e liberdade está baseada nas condições de socialização comunicativa dos indivíduos, em que a ação comunicativa é parte estruturante, impossibilitando - esta é sua crítica a Weber e a Lukács - a coisificação da consciência.

Claus Offe, em 1985, caminha no mesmo sentido. No seu livro, Capitalismo desorganizado (OFFE, 1995), propóe a ultrapassar o marxismo supondo o fim do antagonismo entre trabalho e capital. A base de tal pressuposto implica advogar a sociedade para além da exequibilidade do "emprego" e, em especial no capítulo 5, "Trabalho: categoria sociológica chave?" (OFFE, 1995 , p. 168), argumenta que a centralidade do trabalho enquanto categoria - principalmente no capitalismo avançado - não é explicativa, dado o sistema altamente desorganizado de poder social. Entretanto, Offe reconhece o caráter ad hoc dessas classificaçóes binárias, materialistas versus pós-materialistas, porque uma teoria dinâmica da mudança social - com exceção de Habermas e Bell5 - mas essas classificações permanecem não integradas, em resumo, "[...] não liberando novos campos de ação caracterizados por novos agentes e nova forma de racionalidade" (OFFE, 1995, p. 197).

Ralf Dahrendorf (1992), em obra também publicada no Brasil', ironizando os "pós-ismos" dos autores que se regozijam em viver a "pós-alguma-outra-época", parte da consideração de que as sociedades modernas são sociedades de trabalho, "[...] construídas em torno de uma ética de trabalho e posiçóes ocupacionais", mas aceita que elas "[...] parecem ser conduzidas pela visão e pela perspectiva em aparência crescentemente realista de um mundo sem trabalho" (DAHRENDORF, 1992, p. 152). Argumenta que, de fato, de um fardo, o trabalho se tornou um privilégio, onde a nova riqueza do trabalho, o consumo conspícuo, deriva de uma classe de ociosos, cujos membros estáo "[...] sempre reclamando de não conhecer a diferença entre os dias da semana” (DAHRENDORF, 1992, p. 153). 
A constatação de Dahrendorf (1992), ao estudar os dados dos países da Organização para a Cooperação e Desenvolvimento Econômico (OCDE), é que o desemprego não afeta o crescimento econômico, havendo até uma dissociação entre ambos. E se não é possível criar empregos com níveis menores de pagamento do que os vigentes, então o desemprego é, em sentido monetário estrito, mais barato que o emprego. Pontua aí uma crítica às políticas social-democratas de prometerem mais emprego e organizarem os sistemas educacionais e de formação técnica pela premissa do trabalho, sabedoras, segundo sua opinião, de que o desemprego não afeta muitas das funções nucleares da economia. Cita como exemplos a agricultura e a indústria do setor de manufaturados. Ao fim, no entendimento de Dahrendorf (1992), é necessário dissociar cidadania de trabalho, de não mais se prometer trabalho como direito, ao contrário, de se estabelecer o direito de não trabalhar.

Ou seja, nas palavras do autor, "a classe no velho sentido não é a base predominante do conflito, e quaisquer que sejam as novas linhas de divisão e antagonismo que estejam emergindo, não conduzem a lutas organizadas entre novos ricos e novos despossuídos" (DAHRENDORF, 1992, p. 167). Para o autor, a mobilidade individual assume o lugar da luta de classe. Então, as pessoas lutam por reconhecimento, a partir de uma suposta base comum de cidadania. Mas reconhecendo também que não emergiu nenhum novo conflito comparável aos conflitos de classe, pontua: "uma sociedade que parece aceitar a existência contínua de um grupo que náo tem um vínculo real com ela colocouse a si mesma em risco" (DAHRENDORF, 1992, p. 173). A sociedade sem o trabalho, nessa consideração, é o risco da anomia, pois as exigências de justiça permanecem.

André Gorz, também com ampla publicação no Brasil, tais como Estratégia operária e o neocapitalismo (1968), O socialismo difícil (1968), Crítica da divisão do trabalho (1980), Adeus ao proletariado (1982) e Metamorfoses do trabalho (2003), entre outras obras, destaca a elaboração marxiana, exposta nos Manuscritos de 1844, na ideologia alemã, em $\mathrm{O}$ capital, e reforça a linha de argumentação de apresentar o trabalho geral, tal como nos Grundrisse, que concorre ao conjunto da produção social. Para Marx, segundo Gorz (2003), na produção social o trabalho é posto como uma necessidade social, mas como meio e coisa externa aos indivíduos trabalhadores, associando essa análise também a Durkheim, em Da divisão do trabalho social. Dessa forma, a proletarização dos produtores anuncia-se como força emancipadora porque unificadora racional do processo social. 
Não se trata, ainda segundo Gorz (2003), de propor uma volta ao estatuto do artesão da Idade Média, mas de os que não são nada tornaremse tudo, exatamente porque despojados tornam-se sujeitos universais, não prisioneiros a nenhuma atividade privada particular. Esse é o conteúdo utópico de Marx, segundo Gorz (2003), com essa referida inversão dialética partilhada pelas esquerdas clássicas. Entretanto, para o autor, o caráter utópico dessa formulação emancipadora reside no caráter mutante da sociedade, em que "[...] o declínio da massa dos salários distribuídos e o declínio do preço das produções automatizadas não poderão ser evitados" (GORZ, 2003, p. 234). Em outras palavras, as produções robotizadas prescindem do trabalho geral, permitindo a instituiçáo de um sistema de preços políticos, refletindo escolhas da sociedade, onde a renda seria independente da quantidade de trabalho fornecida, possibilitado pelo custo do trabalho negligenciável nas produçôes robotizadas.

A questão pendente no autor, de certa forma reconhecida ao final do livro citado, é que nada garante que tal sentido caminhe para a emancipaçáo e a autonomia das pessoas, e não em direção a um controle ainda maior. É como se, sem o trabalho, com o adeus ao proletariado, a sociedade ficasse suspensa no ar, o vivo prisioneiro do morto.

Nessa perspectiva, os processos sociais movidos pelo antagonismo e pelo irreconciliável precisariam ser inibidos, porque não vinculados a um sistema social de interação comunicacional, cuja disputa estratégica residiria nas identidades, sendo o multiculturalismo o espaço polifônico onde as assimetrias e disfunções são apresentadas como diferenças e divergências dialógicas.

Antagônicas a essas perspectivas, outras posiçóes, como a de Mészáros (2002), situam-se na necessidade de considerar a capacidade de reestruturação do modo capitalista de exploração, como o sociometabolismo do capital, mais do que do capitalismo propriamente dito. Com essa ênfase no capital, as crises que têm servido como justificativas dos diversos programas das políticas econômicas e sociais reformistas, são em realidade semblantes de uma crise estrutural que expóe como ponto central o antagonismo com o capital como fundação alternativa.

Também na mesma linha crítica de ir além do aspecto fenomênico das interpretaçóes anteriormente citadas, é necessário considerar como recurso metodológico da sociologia a necessidade de expor a fetichização, "[...] sem a qual a desvalorização do trabalho aparece apenas como não trabalho e não como exploração" (SOUSA, 1993, p. 28). Sua supressão exigiria sua negação 
no seu inteiramente contrário. Na verdade, a desvalorização do trabalho tem relação direta, quer dizer, resulta da subsunção do trabalho ao capital, sob a forma de mais-valia, e sua expressão contemporânea como redução do tempo socialmente necessário à produção do valor, fonte da alienação do processo de trabalho sob a forma especificamente capitalista. A eliminação das categorias ontológicas, nesse plano, seria "introduzir a política com um alto grau de indeterminação numa sociedade que não reconhece o que não tem objetividade comercial ou convertibilidade em preços" (SOUSA, 1993, p. 29). Embora, assim considerando, o trabalho como categoria ontológica não perde qualidade analítica, mas é ardilosamente demandada no seu contrário como conceito, porque negatividade, não humaniza, e sim, coisifica.

Nessa direção, Ricardo Antunes, em Adeus ao trabalho? (1995) e em Os sentidos do trabalho (2000), contrariando os autores que idealizam uma conformação "com o capital" (conforme apresentação de Mészáros), sustentando sua permanente supremacia, conjugando emancipaçáo como lazer fora da atividade produtiva, indica como, sob a vigência do capital, não é possível combinar trabalho estranhado com tempo verdadeiramente livre. Para Antunes, referenciando-se em Marx, a substituição do trabalho vivo pelo trabalho morto, o trabalhador "como regulador do processo de produção" (ANTUNES, 2000, p. 212), não é possível plenamente sob a vigência da lei do valor. Não é adequado confundir pós-taylorismo e pós-fordismo com emancipação, daí a afirmativa da necessidade de "uma concepção ampliada do trabalho" para melhor entendêlo na sociabilidade contemporânea. Ou seja, a categoria trabalho mantém sua atualidade como explicativa no âmbito ontológico. Consequentemente, pode-se interpretar como princípio no âmbito formativo, se reafirmado como produtor de valor de uso, próximo do que já propunha Erich Fromm (1963, p. 272) ao defender o princípio do socialismo comunitário, referindo-se aos owenistas, caracterizando como "trabalhador todos os que vivem do seu trabalho, sem lucros adicionais resultantes do emprego de outros".

Para Tumolo (2005), é preciso refinar criticamente essa compreensão embasada numa espécie de viragem e reviragem metodológica de Marx, para quem a categoria trabalho em geral tem na sua formulação a explicação hominizante (produção de valor de uso), mas não suficiente para explicar a valorização do valor, forma especificamente capitalista. Nesse caso, quando a força de trabalho se transforma em mercadoria, "[...] na forma social do capital, a dimensão de positividade do trabalho se constitui pela dimensão de sua 
negatividade, seu estatuto de ser criador da vida humana se constrói por meio de sua condiçâoo de ser produtor da morte humana" (TUMOLO, 2005, p. 255).

Sob tal inspiração, duas conclusóes podem ser ventiladas como mais próximas do que é desenvolvido mais adiante: de um lado, a superação do caráter do trabalho (agora como substrato inteiramente capitalista) é condicionada à superaçáo do capital e de sua forma social, ou seja, não fazendo sentido histórico sua revogação sem superação do capital e sua valorização fetichizada e totalitária; e, por outro lado, o trabalho em geral, como ideal formativo, ao tornar-se produtivo de capital, é histórica e intrinsecamente uma realização social do próprio capital (como indicara Marx), ao contrário de ser um elo (como indicaram Durkheim e Weber) de solidariedade e emancipação.

De fato, uma das questóes mais complexas na epistemologia é certamente a correlação entre o particular e o geral na realidade objetiva e na consciência. Ludwig Feuerbach, sob a crítica de Marx e Engels, partilhava dessa constatação, observando como, de certa forma, a história da filosofia está centralizada nessa questão. Isso passa pela filosofia da antiga Grécia, pelos nominalistas e realistas na Idade Média, pelos materialistas dos tempos modernos até a contemporaneidade, em diferentes tendências: (1) as categorias como independentes da consciência, (2) como essências ideais particulares, ou seus críticos (3) definindo as categorias como ficçōes, (4) outros como formas de pensamento a priori e (5) como a perspectiva mais desenvolvida, a tendência de situar as categorias como imagens que se formam com o desenvolvimento da consciência da realidade objetiva, efetivando os laços reais históricos.

Dessa forma, trata-se de uma ponderação válida, a indicação de que o trabalho "dificilmente pode ser considerado como categoria analítica" (TUMOLO, 2005, p. 256), fora do âmbito da forma social capitalista, por conta de evitar sua abstração ideal e autônoma, ou mesmo a ideia absoluta. Entretanto, também é necessário considerar que, caso seja aceito somente o geral, na realidade objetiva, como objetos singulares, rejeita-se a possibilidade de conceitos e categorias existirem como correlação entre o particular e o geral. As categorias, como formas mais gerais, têm na expressão trabalho essa possibilidade, a representação não separada do objeto real, refletindo as formas universais do ser concreto. Mas, isoladamente, o trabalho não significa nada, apenas especulação, se não relacionado à produção, à mercadoria, à propriedade privada, ao capital etc., onde a categoria trabalho pode existir se seu conteúdo coincide com sua essência, para além do fenômeno, não se confundindo, 
o trabalho, com outras atividades. Assim, o trabalho, como categoria do conhecimento dialético, "é conhecimento vivo, polifacético (cujo número de facetas aumenta sempre), de inumeráveis matizes no modo de abordar a realidade e de aproximar-se a ela" (LENIN, 1980b, p. 12).

Com essas ponderações, é possível então sugerir que, sem considerar o caráter histórico-cultural, o trabalho, como princípio positivo, torna-se uma determinação ideal, inclusive como princípio educativo, se reivindica aí a perspectiva da classe trabalhadora. Ou seja, se não se considera seu conceito como criação de valor, a emancipação formativa ou pedagógica reduz-se ao plano da consciência, perdendo sua ontologia.

As digressões acima foram necessárias como uma excursão para que se possa sustentar o argumento de que a educação, nesses termos, tem também uma função reconhecida na medida em que se justifique socialmente, ou seja, torne-se totalmente instrumental ou utilitária, baseada no trabalho alienante, servidáo do trabalhador, idealizado por Hegel como fundamento da autoconsciência do trabalhador, de sua liberdade, de seu valor humano. Assim, é necessário consignar a conhecida crítica de Marx a essa formulação hegeliana de que essa consciência de sua criação é inseparável da consciência de sua alienação.

Por isso, outro pressuposto que fora relevante à ontologia metafísica e crítica, agora, para ser funcional, deveria e deve ser esvaziado de seu conteúdo, movido de sua paixão pelo negativo - falo aqui do trabalho. $\mathrm{O}$ trabalho, socialmente como ser trabalhador, até como política pública nos governos dos partidos dos trabalhadores e dos socialistas, é "transformado" em ser empreendedor, reapresentado como fenômeno de outro comentado fenômeno, a reestruturação produtiva, eleita categoria central nos discursos de parte da sociologia. Seus conflitos, nesse discurso, destituído do antagonismo, são deslocados da esfera do direito trabalhista, do âmbito do direito positivo instaurado pela revolução burguesa, para ser dirimidos no direito do consumidor.

O Estado também é destituído de toda sua historicidade conflituosa, do estatuto da violência de classe que lhe é intrínseco, para outorgar-se como serviço, como regulação, como agência e como governança. Diluído nessas esferas, não tem por que relacioná-lo às classes sociais, visto que é o espaço 
virtual da sociedade civil burguesa e seus movimentos de empoderamento: comunidades, participação, accountability, consensos, referendos etc.

A educação também aqui é funcional, é a estratégia da tão homenageada cidadania. Portanto, falar em Estado, em classe trabalhadora e, pior - que ousadia -, falar em perspectiva da classe trabalhadora é, na melhor das hipóteses, algo que soa como esotérico.

Assim, o Estado e a educação na perspectiva da classe trabalhadora, tema deste artigo, tem na formulação das respostas mais aceitáveis antes referidas a nulidade do mérito, ou seja, náo deveria nem ser proposta.

São de curta duração essas respostas mais aceitáveis. Cada vez mais curtas, embora refeitas e reapresentadas como um movimento permanente. Como por magia desfaz-se o encanto do liberalismo e nas crises do sistema do capital como sistema social, cada vez mais frequentes, reclamam pelo impossível: o Estado e o trabalho, mais Estado e mais trabalho, para retirar o capital de sua crise de superprodução.

Neste início de século estamos vivendo a patente comprovação desse evento histórico e não mágico. Quando os indicadores financeiros pareciam afiançar lucros formidáveis, seus agentes tinham nessa propagação a estratégia para correr em busca de proteçáo dos seus ativos, que poderiam virar fumaça rapidamente. Enquanto os propagandistas do mercado financeiro e os cientistas sociais apologéticos do sistema iludiam as pessoas, em especial os trabalhadores, apresentando como estático o que é dinâmico, os maiores donos dos maiores capitais se protegiam, como um corpo único, em ilhas de segurança máxima, isolando seus ativos da bancarrota e chamando o Estado para movimentar seus recursos em direção às salvaguardas do capital.

O que parecia abolido pela doutrina liberal e neoliberal, apoiado pelas vertentes políticas social-democratas e socialistas, aparece com toda sua substância social, para além do formalismo da igualdade jurídica. Objetivamente e rapidamente, os governos dos países mais atingidos na Europa e na América mobilizaram todos os recursos financeiros acumulados da poupança que extorquiram dos trabalhadores para segurar a queda vertiginosa dos lucros, protegendo o capital nas suas diferentes aplicaçóes: bancárias, industriais, imobiliárias, entre outras, embora articuladas como capital financeiro.

$\mathrm{Na}$ atual conjuntura, desde 2007 a crise do discurso conservador assume seu patamar mais ardiloso ideologicamente, ou seja, o conservadorismo não 
assume o discurso social-democrata, ao contrário, indica categoricamente: precisamos todos sermos conservadores.

E, o pior, parte expressiva dos partidos que se autorreferenciavam como de origem trabalhista apoia, como vanguarda, levando junto seus sindicatos.

A lógica das medidas: o Estado doa dinheiro para bancos em dificuldades, desonera o capital dos impostos, onera os trabalhadores com mais impostos, com congelamento e mesmo diminuição dos salários e dispensa de trabalhadores do setor público e apoio à demissão dos trabalhadores do setor privado. Isso sob a justificativa de que o Estado tenha margem orçamentária para aplicar no setor privado e promover guerras de invasão reforçando as heterenomias (FERNANDES, 1975, 2006) entre países e garantir a espoliação dos seus recursos.

Paradoxalmente, para não falar contraditoriamente - pois as forças conservadoras usam, mas não reconhecem a dialética -, o argumento básico é que tais medidas visam gerar mais empregos e renda. Caso contrário, com a crise ameaçando a estabilidade dos laços sociais, seria a própria sociedade que estaria em questão. Ora, não há declaração de guerra de classe mais escancarada mundialmente.

Além do Estado, outra positividade reivindicada no discurso conservador é o trabalho. Ao contrário das formulaçóes dos autores citados na primeira parte deste artigo, quase todos os governos, sejam os denominados à direita ou centro, sejam os denominados de esquerda, clamam pelo trabalho, por mais trabalho. As políticas públicas salvacionistas, sejam de emergência, sejam de longo prazo, pautam seu repertório com o trabalho como centralidade. Até mesmo a nova chefe do FMI, a conservadora Christine Lagarde, apresentouse na nova investidura dizendo que "o desemprego é uma questão chave [...] temos que fazer muito nesse terreno" (LAGARDE, 2011).

Pois bem, estariam todos convergindo para a centralidade do trabalho e do Estado? Não estaríamos táo fora de moda, quando a literatura das ciências sociais em geral, da grande imprensa, dos seminários e colóquios nacionais e internacionais voltam à temática do trabalho e Estado, embora certas vezes ainda envernizada como políticas públicas.

Como dito anteriormente, esta é uma típica formulação que busca as respostas mais aceitáveis. O contexto da crise aqui referido, que para uns parecia uma marola passageira e para outros uma correção dos rumos do sistema 
do capital, expõe o movimento de mais um ciclo de restauração burguesa. Sucedâneas das revoluçóes burguesas, as movimentaçóes da classe apoderada do capital, que seguiram pelo menos desde a revolução francesa, e se fazem como restauração de seus termos originários: a exploração do trabalho como fonte de dominaçấo social, mediada em todas as demais relaçóes sociais, inclusive as educacionais e morais. Suas crises são crises restauradoras da dominação de classe originária. É o que vivemos no atual ciclo.

Reconhecemos em Marx (1984) a possibilidade ontológica do trabalho quando a economia política o definiu como instrumental. Mas também é necessário reconhecer, na sua crítica, como o trabalho subsumido ao capital é força de trabalho, é mercadoria (MARX, 1975).

O trabalho perde sua positividade como categoria para ser um ardil da história, como negatividade nega o capital, negando-se como força de trabalho, sem o que não há o que se denominar perspectiva da classe trabalhadora. Entendido assim, quando se repóem como respostas à crise a centralidade do trabalho e a do Estado com a mediação violenta aceitável, na realidade o que se está fazendo, como movimento, é restaurar a centralidade política do capital.

Dito claramente, as atuais governanças nacionais e mundiais articulamse como classe numa violenta e ideológica restauração do capitalismo como sistema social, colocando como chave a centralidade política do capital, que é a substância do que parece ser uma retomada da centralidade do trabalho.

Como desdobramento, há uma vertente no debate sobre a educação de que o trabalho como princípio educativo corresponderia à perspectiva da classe trabalhadora. Para o movimento de restauração burguesa frente a um sistema ameaçado pela guerra de classes e ambiental, a educação ao trabalho é produto da fetichização da sociedade como totalitarismo: quer dizer, não deixar existir nada fora do mercado, não deixar existir vida que não seja convertida em preços. Consolidado isso, cristaliza-se que não temos alternativa. Posto assim, ao negar-se a política, o Estado é confirmado como aquilo que nunca deixou de ser e que LENIN pontuou em O Estado e a Revolução (1978) e El marxismo y el Estado (1980a), dentre outros textos: contribui como mediação alienadora apresentando como público o que não pertence aos trabalhadores, alienados em si mesmos (não apenas como exteriorização), no ato da produçẫo, tornando-se estes mercadoria que, vendida, os faz estranhos com a perda de si mesmos. Mas não é a religião, o gênero, a etnia, o trabalho ou a educação que lhes reconstituem a identidade, pois já estão alienados como gênero, não 
apenas como indivíduos. Sob essas condições, não é o trabalho (produtivo) a perspectiva da classe trabalhadora, e sim da classe capitalista.

Nesta perspectiva de classe, da classe capitalista, o atual ciclo de restauração de pouco mais de 20 anos, como diz Alain Badiou (2007, p. 49), "[...] é apenas um momento da história que declara impossíveis e abomináveis as revoluções, e natural assim como excelente a superioridade dos ricos".

Talvez estejamos no momento de repetir LENIN, o que denuncia a falsidade da tolerância liberal, o LENIN intolerável.

Até Marx, como diz Slavoj Zizek (2005, p. 7), é tolerado em Wall Street, "o Marx poeta das mercadorias", que "[...] fez descriçôes perfeitas da dinâmica capitalista e da reificação de nossas vidas cotidianas".

Mas LENIN, este é intolerável, até para parcelas da esquerda que o considerariam, mas deixando no seu túmulo o seu principal legado, "o implacável enfoque na luta de classes" (ZIZEK, 2005, p. 7).

Marx é tolerado também nas universidades, nos grupos de estudo (sabemos que Fernando Henrique Cardoso, o ex-presidente do Brasil, foi um dos fundadores de um desses grupos na USP), como bibliografia em dissertaçóes e teses e como centro de colóquios acadêmicos.

Mas LENIN raramente está presente como referência bibliográfica, e muito menos como referência teórica. Não haveria razão de ser numa era em que a revolução e o socialismo parecem coisas do passado.

Contudo, a verdade das catástrofes não reside nas academias ou nos partidos da restauração capitalista. E sim, na possibilidade da revolução, de esmagar o Estado burguês por outras formas sociais que abandonem o vocabulário e a gramática da tradição política. Isso significa que repetir LENIN é deslocar o âmago do marxismo, como diz Florestan Fernandes (1978), para as condiçôes concretas da ação política e da transformação política. Se antes semelhante elemento político estava incluído no marxismo como previsão, com LENIN "converte-se no ponto central da indagação marxista, e do próprio marxismo como movimento político" (FERNANDES, 1978, p. 17).

\section{Considerações finais}

Retornando agora ao início deste artigo, o que unicamente dá mérito à questão, na sua paixão do negativo, momento da vontade política, da 
irreconciliação, não é se negar a pensar, não é aceitar como abomináveis as revoluçôes, como postula a restauração capitalista - que tem na centralidade do trabalho mercadoria esgotada ao mínimo necessário à sua centralidade política.

O que unicamente lhe dá o mérito, ou seja, que a faz existir como superação e emancipação, negação da negação, é colocar o Estado e a educação sob outra centralidade, a centralidade política da revolução. Esta é, historicamente, a real centralidade do trabalho, quando negação radical do trabalho produtivo de capital.

Ante a restauração capitalista, não adianta colocar o trabalho como princípio educativo e o Estado como garantia dos direitos e da educação pública se a revolução não for o princípio educativo orientador.

É possível a centralidade política dos trabalhadores (que não é o mesmo que centralidade do trabalho) como negação da centralidade política do capital quando articulada epistemologicamente, dialeticamente - como diria LENIN (1980b) em sua ficha de leitura Em torno da dialética - e politicamente como teoria revolucionária.

\section{Notas}

${ }^{1}$ E nem todo marxismo é substantivamente crítico.

${ }^{2}$ Revolucionários, permitam-me aqui iniciar citando um adjetivo também considerado indigesto em alguns ambientes.

${ }^{3}$ Algumas referências datam do final dos anos 1960.

${ }^{4}$ Aqui entendida por Habermas, já em 1981, como uma categoria da teoria marxista.

${ }^{5}$ Daniel Bell, autor de The coming of post-industrial society, escrito nos anos 1960 e publicado em 1973.

${ }^{6}$ O conflito social moderno, publicado no Brasil em 1992, tradução da edição inglesa de 1988. 


\section{REFERÊNCIAS}

ANTUNES, Ricardo. Adeus ao trabalho? Ensaio sobre as metamorfoses e a centralidade do mundo do trabalho. 2. ed. São Paulo: Cortez, 1995.

Os sentidos do trabalho: ensaios sobre a afirmação e a negação do trabalho. São Paulo: Boitempo, 2000.

BADIOU, Alain. O século. São Paulo: Ideias \& Letras, 2007.

DAHRENDORF, Ralf. O conflito social moderno: um ensaio sobre a política da liberdade. Rio de Janeiro/São Paulo: Jorge Zahar/Edusp, 1992.

FERNANDES, Florestan. Capitalismo dependente e classes sociais na América Latina. Rio de Janeiro: Zahar, 1975.

LENIN: política. São Paulo: Ática, 1978.

A revolução burguesa no Brasil: ensaios de interpretação sociológica.

São Paulo: Globo, 2006.

LAGARDE diz que desemprego é preocupação para o FMI. Folha de $S$.

Paulo, São Paulo, 6 jul. 2011. Disponível em: <www1.folha.uol.com.br/ mundo/939689-lagarde-diz-que-desemprego-e-preocupacao-para-o-fmi. shtml>. Acesso em: 7 jul. 2011.

FROMM, Erich. Psicanálise da sociedade contemporânea. Rio de Janeiro: Zahar, 1963.

GORZ, André. Metamorfoses do trabalho: crítica da razão econômica. São Paulo: Annablume, 2003.

HABERMAS, Jürgen. Teoría de la acción comunicativa, I e II: racionalidad de la acción y racionalización social. Madrid: Taurus, 2001.

LENIN, Vladimir Ilitch Ulianov. O Estado e a Revolução. São Paulo: Hucitec, 1978.

El marxismo y el Estado: materiales preparatórios para el libro El Estado y la Revolución. Moscú: Progresso, 1980a.

En torno a la cuestion de la dialectica. Moscú: Progresso, 1980b.

MARX, Karl. Capitulo inédito d'O Capital: resultado do processo de produção imediato. Porto: Escorpiáo, 1975.

PERSPECTIVA, Florianópolis, v. 31, n. 1, 29-44, jan./abr. 2013

http://www.perspectiva.ufsc.br 
MARX, Karl. Manuscritos economía y filosofía. Madrid: Alianza, 1984.

MÉSZÁROS, István. Para além do capital. São Paulo: Boitempo, 2002.

OFFE, Claus. Capitalismo desorganizado. São Paulo: Brasiliense, 1995.

SOUSA, Fernando Ponte de. Uma sociologia do trabalho sem o trabalho? Ciências Humanas, Florianópolis, SC, v. 10, n. 14, p. 7-30, set. 1993.

TOURAINE, Alain. A sociedade post-industrial. Lisboa: Moraes, 1970.

TUMOLO, Paulo Sergio. O trabalho na forma social do capital e o trabalho como princípio educativo: uma articulação possível? Educação \& Sociedade, Campinas, SP, v. 26, n. 90, p. 239-265, jan./abr. 2005.

ZIZEK, Slavoj. Às portas da revolução: escritos de LENIN de 1917. São Paulo: Boitempo, 2005. 


\section{El Estado y la educación The State and education from desde la perspectiva de la a working class perspective clase trabajadora \\ Abstract}

\section{Resumen}

En el presente artículo, se destacan algunos autores que cuestionan la categoría trabajo como central y otros que critican esta posición, en esa dirección se busca otras posibilidades para el debate. A partir de esa discusión entendemos que, sin considerar su carácter históricocultural, el trabajo, como principio positivo, se torna una idealización, inclusive como principio educativo en caso de reivindicar la perspectiva de la clase trabajadora. Es decir, si no se considera su concepto como creación de valor, la emancipación formativa queda reducida al plano de la conciencia, pierde su ontología. En ese marco, la centralidad política del capital es la sustancia de lo que parece ser la retomada de la centralidad del trabajo. Su real antagonismo es el de colocar el Estado y la educación bajo otra centralidad, la teoría revolucionaria como principio educativo orientador.

Palabras clave: Trabajo. Educación. Crisis.

\section{Fernando Ponte}

E-mail: fernando_ponte@uol.com.br

\begin{abstract}
This article, highlighting several authors who emphasize the centrality of the labor category and others who criticize this position, attempts to present another side of the debate. It suggests that if its historical-cultural character is not considered, work - as a positive principle - becomes an idealization. It is even an educational principle, as is claimed by the working class perspective. In other words, if the concept is not seen as being one that creates value, formative emancipation is reduced to the plane of consciousness, and loses its ontology. In this scenario, the political centrality of capital is the substance that appears to recapture the centrality of labor. Its true challenge is to place the state and education under a different centrality, with revolutionary theory as the guiding educational principle.
\end{abstract}

Keywords: Work. Education. Crisis.

Recebido em: 6/3/2012

Versáo final recebida em: 9/8/2012

Aprovado em: 24/8/2012 